\title{
On the Occurrence of Aphroceras (Leucandra) cliarensis Stephens near Plymouth.
}

\author{
By
}

\author{
Arthur Dendy, D.Sc., F.R.S.
}

In July, 1912, a paper was published in the Proceedings of the Royal Irish Academy (Vol. XXXI) on the Marine Porifera of Clare Island, by Miss Jane Stephens, in which the authoress gives an excellent account of a new species of Calcareous Sponge, Leucandra cliarensis. In April of the same year I happened to be working at the Marine Laboratory at Plymouth, and my friend Mr. Orton brought me several specimens of a very pretty little calcareous sponge just collected by him at Wembury Bay. I was too much occupied with other work to examine these carefully at the time, but simply preserved them in spirit. Recently I have examined them in detail, and find, curiously enough, that they belong to the species described by Miss Stephens from Clare Island on the west coast of Ireland.

It is unnecessary, in view of the description already published by Miss Stephens, to give a detailed account of the sponge in this place. I may, however, point out the salient features by which it is easily recognized. The external appearance is characteristic. The individuals are usually solitary and less than an inch in height. The form of the sponge, however, varies greatly, from quite slender to almost globular. There is usually a single terminal vent. The surface, when viewed under a pocket-lens, exhibits a glistening appearance, with longitudinal striations due to the presence of gigantic oxea in the dermal cortex. This arrangement of the large oxea brings about a close resemblance to species of the genus Ute. The canal system is, however, typically leuconoid, with small, rounded flagellate characters.

The most remarkable and constant specific character appears to be the presence of enormous sabre-shaped apical rays on the gastral quadriradiates, sometimes reaching a length of $0.5 \mathrm{~mm}$., and, of course, projecting into the gastral cavity.

In our recently published paper on "The Classification and Phylogeny 
of the Calcareous Sponges, etc." (Proc. Zool. Soc. Lond., Sept., 1913) Mr. Row and I have placed the species in the genus Aphroceras Gray, which is distinguished from Leucandra by the presence of a dermal layer of gigantic longitudinal oxea. This genus cannot, however, be very sharply separated from Leucandra, and in A. cliarensis a great many of the large oxea lie obliquely in the deeper parts of the sponge, as in many Leucandras. Nevertheless, there are sufficient of the large oxea in the dermal layer to give the surface of the sponge the longitudinally striated (and not obviously hispid) character of Aphroceras.

The discovery of this interesting species at Plymouth contributes an interesting addition to the marine fauna, not only of the district, but also of Great Britain ; while the fact that it should have turned up there so shortly before the appearance of Miss Stephens' memoir is one of those curious coincidences which so frequently surprise the systematic zoologist. 